\title{
Hydrocarbon Oxidation Catalyzed by Iron and Manganese Porphyrins Anchored on Aminofunctionalized Supports
}

\author{
André L. Faria, Tatiana O. C. Mac Leod, Valéria P. Barros and Marilda D. Assis* \\ Departamento de Química, Faculdade de Filosofia, Ciências e Letras de Ribeirão Preto, \\ Universidade de São Paulo, Av. Bandeirantes, 3900, 14040-901 Ribeirão Preto-SP, Brazil
}

As metaloporfirinas de segunda geração (MePs), cloreto de [5,10,15,20-tetraquis(pentafluorofenil)porfirinaferro(III)], FeP, e cloreto de [5,10,15,20-tetraquis(pentafluorofenil)porfirinamanganês(III)], MnP, foram covalentemente ancoradas em suportes aminofuncionalizados, com o objetivo de preparar catalisadores sólidos seletivos para a oxidação de compostos orgânicos. Montmorillonita K10 funcionalizada com 3-aminopropiltrietoxissilano (Mont1) ou com 3-cloropropiltrietoxissilano seguida por reação com 1,6-diaminoexano (Mont2), e sílica gel funcionalizada com 3-aminopropiltrietoxissilano (Sil1) ou modificada com 3-cloropropiltrietoxissilano seguida por reação com 1,6-diaminoexano (Sil2) foram preparadas e caracterizadas por UV-Vis, IR, EPR, TGA e difratometria de raios X. As atividades catalíticas das MePs imobilizadas nestes suportes foram investigadas na oxidação de ( $Z$ )-cicloocteno, cicloexano e estireno por iodosilbenzeno ( $\mathrm{PhIO}$ ) ou $\mathrm{H}_{2} \mathrm{O}_{2}$. Os sistemas estudados foram catalisadores eficientes da oxidação de todos os substratos, especialmente utilizando PhIO como oxidante. Não se observou lixiviamento das MePs dos suportes, indicando que a ligação covalente é um método muito eficiente para a imobilização de catalisadores. As FePs imobilizadas foram catalisadores mais eficientes que as correspondentes MnPs, mesmo quando imidazol foi empregado como um co-catalisador para as MnPs ancoradas. Embora os rendimentos de produtos oxidados utilizando $\mathrm{H}_{2} \mathrm{O}_{2}$ tenham sido mais baixos que aqueles obtidos com $\mathrm{PhIO}$, alguns sistemas heterogêneos envolvendo MePs foram mais eficientes que as correspondentes MePs em solução, tanto em termos de rendimento de produto quanto de seletividade.

The second-generation metalloporphyrins (MePs) [5,10,15,20-tetrakis(pentafluorophen yl)porphyrin iron(III)] chloride, FeP, and [5,10,15,20-tetrakis(pentafluorophenyl)porphyrin manganese(III)] chloride, $\mathrm{MnP}$, were covalently attached to aminofunctionalized supports, with a view to preparing selective solid catalysts for the oxidation of organic compounds. Montmorillonite K10 functionalized with 3-aminopropyltriethoxysilane (Mont1) or modified with 3-chloropropyltriethoxysilane followed by reaction with 1,6-diaminohexane (Mont2), and silica gel functionalized with 3-aminopropyltriethoxysilane (Sil1) or modified with 3-chloropropyltriethoxysilane followed by reaction with 1,6-diaminohexane (Sil2) were synthesized and characterized by UV-Vis and IR spectroscopies, EPR, TGA, and X-ray diffractometry. The catalytic activities of the MePs immobilized on these supports were investigated for the oxidation of $(Z)$-cyclooctene, cyclohexane and styrene by $\mathrm{PhIO}$ or $\mathrm{H}_{2} \mathrm{O}_{2}$. The studied systems were efficient catalysts for the oxidation of all substrates, especially when $\mathrm{PhIO}$ was the oxidant. There was no MeP leaching from the supports, indicating that covalent binding is a very efficient method for catalyst immobilization. The immobilized FePs were more efficient catalysts than the corresponding MnPs, even when imidazole was employed as a cocatalyst for the supported MnPs. Although the yields of oxidized products obtained with $\mathrm{H}_{2} \mathrm{O}_{2}$ were lower than those achieved with $\mathrm{PhIO}$, some heterogeneous MeP systems were more efficient than the parent MePs in solution, both in terms of product yield and selectivity.

Keywords: supported metalloporphyrins, catalysis, aminofunctionalized supports, metalloporphines

*e-mail: mddassis@usp.br 


\section{Introduction}

Immobilization of catalysts such as metalloporphyrins (MePs) and salen complexes on inorganic matrices (silica, alumina, zeolites, anionic and cationic clays) and organic resin polymers has attracted researchers' attention in recent years, especially in the case of hydrocarbon oxidation by single oxygen donors like iodosylbenzene and peroxides. ${ }^{1-5}$ Catalyst design is based on the use of different metallocomplexes, supports and immobilization techniques, which should lead to selective, stable and high-turnover catalytic systems. Other advantages of heterogeneous catalysis include easy catalyst recovery and reuse, and generation of more stable active catalytic species. ${ }^{6}$

Clays have been widely employed as supports for metallocomplexes over the last few years. ${ }^{7-10}$ Mineral clays are particularly interesting because of their surface chemistry and the properties associated with chemical intercalation. ${ }^{11}$ Intercalation chemistry involves hostguest assemblies where the host is a lamellar compound that can incorporate guests ranging from simple cations to large inorganic species, organic molecules or ions, coordination compounds, and organometallics. Smectite, and in particular montmorillonite, is the most extensively studied family of clays due to its wide range of chemical compositions, its intercalation and ion exchange properties, and its ability to expand and undergo pillarization. ${ }^{12}$ The type of bond formed between the metallocomplex and the support is of utmost importance, and immobilization through covalent binding is particularly interesting because it avoids catalyst leaching from the support, makes the active catalytic species more stable, and offers many options concerning the bond established between the catalyst and the support.

Our research group has been devoted to the preparation of efficient, reusable catalytic systems for the oxidation of organic compounds. In a previous work, we reported on the use of an iron(III) porphyrin covalently attached to two series of aminofunctionalized magnesium hybrid phylllosilicates as catalyst for the oxidation of (Z)-cyclooctene and styrene. These systems efficiently catalyzed the oxidation of these hydrocarbons and were easily recovered from the reaction medium and reused in subsequent reactions.

In this work, the catalytic activity of the metallocomplexes [5,10,15,20-tetrakis(pentafluorophenyl)porphyrin iron(III)] chloride, FeP, and [5,10,15,20-tetrakis(pentafluorophenyl) porphyrin manganese(III)] chloride, MnP, immobilized on aminofunctionalized montmorillonite $\mathrm{K} 10$ or silica by covalent binding was investigated in the oxidation of alkanes and alkenes by iodosylbenzene or hydrogen peroxide.

\section{Experimental}

\section{Materials}

All reagents were commercially available from Aldrich, Sigma or Fluka and were of analytical grade purity unless otherwise stated. Iodosylbenzene ( $\mathrm{PhIO}$ ) was prepared by hydrolysis of iodosylbenzene diacetate, according to the method of Sharefkin and Saltzmann, ${ }^{13,14}$ its purity was $94 \%$ as measured by iodometric titration. ${ }^{15}$ Hydrogen peroxide was stored at $5{ }^{\circ} \mathrm{C}$ and titrated periodically. The alkenes $(Z)$ cyclooctene and styrene were purified on a short activated basic alumina column (Merck) immediately before use. The free base porphyrin 5,10,15,20-tetrakis(pentafluorophenyl) porphyrin $\left(\mathrm{H}_{2} \mathrm{TFPP}\right)$ was purchased from MidCentury.

Synthesis of the MePs (Me = Mn or Fe)

The MePs were prepared by refluxing the free base $\mathrm{H}_{2}$ TFPP (0.1 g per $0.094 \mathrm{mmol}$ ) with manganese(II) acetate tetrahydrate $(0.9 \mathrm{~g}$ per $0.92 \mathrm{mmol})$ or iron(II) chloride tetrahydrate $(0.37 \mathrm{~g}$ per $1.8 \mathrm{mmol})$ in dimethylformamide $(60 \mathrm{~mL})$ for $8 \mathrm{~h}$ under argon atmosphere, following the method described by Adler et al. ${ }^{16}$ The DMF was firstly bubbled with argon for $2 \mathrm{~h}$ in order to remove any amine formed by its decomposition. To remove a small amount of unreacted free base porphyrin, the $\mathrm{MeP}$ was purified by silica column chromatography using dichloromethane as eluent. The pure MeP was then eluted with dichloromethane/methanol 1:1. After solvent removal, the MeP was dissolved in dichloromethane and shaken with a few drops of $\mathrm{HCl}\left(6 \mathrm{~mol} \mathrm{~L}^{-1}\right)$, to ensure that chloride was the axial ligand. This procedure gave $90 \mathrm{mg}(0.085 \mathrm{mmol})$ of the required FeP (90\% yield), UV-Vis $\lambda_{\text {max }} / \mathrm{nm}: 350,410$ (Soret, $\left.\varepsilon=1.110^{4} \mathrm{~L} \mathrm{~mol}^{-1} \mathrm{~cm}^{-1}\right), 504$ and 628 ; and $770 \mathrm{mg}(0.78 \mathrm{mmol})$ of the required $\mathrm{MnP}$ ( $85 \%$ yield), UV-Vis $\lambda_{\text {max }} / \mathrm{nm}: 366,456$ (Soret, $\varepsilon=10^{4} \mathrm{~L} \mathrm{~mol}^{-1} \mathrm{~cm}^{-1}$ ), 550 .

Synthesis of aminated montmorillonite (MontX, where $X=1$ and 2 )

The aminofuctionalization of montmorillonite $\mathrm{K} 10$ with the aminopropylsilyl group was carried out as described by Mansuy and co-workers. ${ }^{17}$

\section{Preparation of $\mathrm{H}^{+}-\mathrm{K} 10$}

A suspension of montmorillonite $\mathrm{K} 10(2 \mathrm{~g})$ in $\mathrm{HCl}$ $\left(0.01 \mathrm{~mol} \mathrm{~L}^{-1}\right)$ was kept under magnetic stirring at room temperature for $2 \mathrm{~h}$. The clay was then washed with distilled water until neutral $\mathrm{pH}$, followed by washing with ethanol $(20 \mathrm{~mL})$ and anhydrous ethyl ether $(20 \mathrm{~mL})$. The clay was dried in an oven for $24 \mathrm{~h}$, at $80^{\circ} \mathrm{C}$. 
Preparation of 3-aminopropyltriethoxysilane-K10, Mont1

3-Aminopropyltriethoxysilane $(560 \mu \mathrm{L})$ was added to a suspension of $\mathrm{H}^{+}-\mathrm{K} 10(\mathrm{ca} .2 \mathrm{~g})$ in anhydrous toluene $(15 \mathrm{~mL})$, previously treated with $\mathrm{P}_{2} \mathrm{O}_{5}$ for $24 \mathrm{~h}$ and distilled. The resulting mixture was stirred under argon for $48 \mathrm{~h}$. After cooling, the 3-aminopropyl-functionalized clay Mont1 was filtered and washed with toluene $(20 \mathrm{~mL})$ and ethyl ether $(20 \mathrm{~mL})$, and dried in an oven for $24 \mathrm{~h}$, at $80^{\circ} \mathrm{C}$.

Preparation of N-(6-aminohexyl)-3-aminopropyltriethoxysilane, Mont2

3-Chloropropyltriethoxysilane $(2 \mathrm{~mL})$ was added to a suspension of $\mathrm{H}^{+}-\mathrm{K} 10(c a .2 \mathrm{~g})$ in anhydrous toluene $(15 \mathrm{~mL})$, previously treated with $\mathrm{P}_{2} \mathrm{O}_{5}$ for $24 \mathrm{~h}$ and distilled. The resulting mixture was stirred under argon for $48 \mathrm{~h}$. After cooling, the 3-chloropropyl-functionalized K10 solid was filtered and washed with toluene $(20 \mathrm{~mL})$ and ethyl ether $(20 \mathrm{~mL})$, and dried in an oven for $24 \mathrm{~h}$, at $80^{\circ} \mathrm{C}$. The freshly prepared 3-chloropropyl-functionalized$\mathrm{K} 10(2 \mathrm{~g})$ was added to 1,6-diaminohexane $(1.2 \mathrm{~g})$ and toluene $(30 \mathrm{~mL})$ under argon atmosphere, and kept under magnetic stirring at $80{ }^{\circ} \mathrm{C}$ for $24 \mathrm{~h}$. After cooling, the reaction mixture was filtered, and the resulting solid was washed with $p$-xylene $(20 \mathrm{~mL})$, dichloromethane $(20 \mathrm{~mL})$, acetone $(20 \mathrm{~mL}), \mathrm{NaOH}\left(20 \mathrm{~mL}, 1 \mathrm{~mol} \mathrm{~L}^{-1}\right)$, deionized water (until $\mathrm{pH} 7$ ), and methanol (20 mL). The aminofunctionalized clay Mont2 was dried in vacuum overnight, at $80^{\circ} \mathrm{C}$.

Synthesis of aminated silica (SilX, where $X=1$ and 2)

The 3-aminopropyl-functionalized silica support was supplied by Aldrich (CAS 36,425-8, $1.5 \mathrm{mmol}$ of amino group per $\mathrm{g}$ ). This aminofunctionalized support was designated Sill.

To prepare Sil2, we firstly synthesized the corresponding 3 -chloropropylsilica by reacting a suspension of silica gel (13 g, 400-600 mesh) with a solution of 3-chloropropyltrimethoxysilane $(12 \mathrm{~mL}, 0.065 \mathrm{~mol})$ in toluene $(100 \mathrm{~mL})$. This reaction was performed under argon atmosphere and magnetic stirring, at $80{ }^{\circ} \mathrm{C} .{ }^{18}$ After $14 \mathrm{~h}$, the reaction mixture was filtered; the white solid was washed with toluene, acetone and water until neutral $\mathrm{pH}$, and dried in a vacuum pump at $140{ }^{\circ} \mathrm{C}$. Aminofunctionalization of the 3-chloropropyl silica was carried out by mixing the 3 -chloropropylsilica $(1.0 \mathrm{~g})$ with 1,6-diaminohexane $(6.0 \mathrm{~g})$ and toluene $(30 \mathrm{~mL})$, under argon atmosphere and magnetic stirring, at $80{ }^{\circ} \mathrm{C}$. After $24 \mathrm{~h}$, the mixture was filtered; the solid was washed with p-xylene $(20 \mathrm{~mL})$, dichloromethane $(20 \mathrm{~mL})$, acetone
(20 mL), $\mathrm{NaOH}\left(20 \mathrm{~mL}, 1 \mathrm{~mol} \mathrm{~L}^{-1}\right)$, deionized water (until $\mathrm{pH} 7)$, and methanol (20 mL). This aminofunctionalized silica was dried in vacuum overnight, at $140^{\circ} \mathrm{C}$, and was designated Sil2.

\section{MeP immobilization}

Supported catalysts were prepared by reacting the MeP $(4.7 \mu \mathrm{mol})$ with one of the aminofunctionalized supports $(0.5 \mathrm{~g})$ in ethylene glycol $(60 \mathrm{~mL})$ at $150{ }^{\circ} \mathrm{C}$, under argon atmosphere and magnetic stirring, for $10 \mathrm{~h}$. The resulting solid was filtered and extracted for $24 \mathrm{~h}$ with $\mathrm{CH}_{2} \mathrm{Cl}_{2}$, and for other $24 \mathrm{~h}$ with $\mathrm{CH}_{3} \mathrm{OH}(24 \mathrm{~h})$, using a Soxhlet procedure. The solid was then dried at $80{ }^{\circ} \mathrm{C}$ for $24 \mathrm{~h}$. The MeP loading on the supports was determined by UV-Vis spectroscopy, by measuring the total amount of unloaded $\mathrm{MeP}$ that remained in the reaction solution and in the washings from the Soxhlet procedure.

After anchoring the $\mathrm{MeP}$, the free $-\mathrm{NH}_{2}$ groups on the surface of the supports were protected by refluxing the supported catalyst $(c a .100 \mathrm{mg})$ with distilled acetic anhydride $(15 \mathrm{~mL})$ for $21 \mathrm{~h} .{ }^{18}$ The resulting solids were washed with deionized water up to neutral $\mathrm{pH}$. The solids were subsequently washed with dichloromethane and then methanol in a Soxhlet apparatus, and dried under vacuum. The MeP loading was obtained by UV-Vis spectroscopy, by measuring the amount of $\mathrm{MeP}$ in the combined washings.

\section{Alkene and alkane oxidation}

In a typical oxidation reaction, the supported catalyst (ca. $20 \mathrm{mg}$, corresponding to $0.25 \mu \mathrm{mol}$ of $\mathrm{MeP}$ ) was stirred with the substrate $(500 \mu \mathrm{mol})$ in dichloroethane $(1.5 \mathrm{~mL})$, and the reaction was then initiated by addition of PhIO $(25 \mu \mathrm{mol})$. The reactions were monitored by removing $0.5 \mu \mathrm{L}$ samples for $\mathrm{GC}$ analysis. All reactions were carried out at room temperature, under magnetic stirring. Recycling of the supported catalyst was carried out with the solid recovered by filtration after the oxidation reaction. The recovered solid catalyst was washed with methanol and dried prior to reuse. For the reactions carried out in the absence of oxygen, the solid MeP and $\mathrm{PhIO}$ were thoroughly flushed with argon prior to the addition of the substrate and dichloroethane, which had also been previously flushed with argon. Argon was also flushed over the solution throughout the reaction. For reactions in the presence of a co-catalyst, $\mathrm{MnP}$ and imidazole (1:30 molar ratio) were stirred in a dichloromethane/acetonitrile (1:1) solvent mixture, and hydrogen peroxide $(30 \%, \mathrm{~m} / \mathrm{V})$ was added with a microsyringe. 
Control reactions were carried out using the unloaded supports and with the supported catalyst in the absence of the oxidant.

\section{Equipment}

The powder X-ray diffraction (XRD) data were recorded on a Siemens D5005 diffractometer, using a graphite monochromator and $\mathrm{Cu} \mathrm{K}_{\alpha}$ emission lines. The solid samples were spread on a glass plate, and the data were collected at room temperature over the range $2^{\circ}-50^{\circ}$. The infrared spectra were recorded from 2000 to $400 \mathrm{~cm}^{-1}$ on a Nicolet 5ZDX Fourier transform infrared (FT-IR) spectrometer. The samples were dispersed in $\mathrm{KBr}$ and pressed into pellets. The EPR spectra of the supported catalysts were recorded using a Varian E-4 spectrometer operating in the $\mathrm{X}$-band frequency $(9 \mathrm{GHz})$, with a gain of $10^{3}$, microwave power of $200 \mathrm{~mW}$, and amplitude modulation of $10 \mathrm{G}$ at liquid nitrogen temperature. UV-Vis spectra were obtained with a Hewlett-Packard 8452 diode array spectrometer. The spectra were recorded in $2 \mathrm{~mm}$ path length quartz cells (Hellma). A suspension of either the supported catalyst or a mixture of the supported catalysts and the support itself in $\mathrm{CCl}_{4}$ was used to measure the Soret band of the immobilized systems. Thermogravimetric analysis (TGA) and differential thermal analysis (DTA) were carried out using a Thermal Analyst TA Instrument SDT Q 600 Simultaneous DTA-TGA-DSC, in nitrogen, at a heating rate of $10{ }^{\circ} \mathrm{C} \mathrm{min}-1$, from 25 to $850{ }^{\circ} \mathrm{C}$. Specific surface areas were determined by analyzing the nitrogen adsorption isotherms on a physical adsorption analyzer (Micrometrics AccSorb 2100E). The GC analyses were performed on a Varian Star 3400CX chromatograph with a hydrogen flame ionization detector using a DB-wax $(1 \mu \mathrm{m}$ thickness) megabore column ( $30 \mathrm{~m}$ x $0.538 \mathrm{~mm}$ ). Nitrogen was used as the carrier gas. The results were recorded and processed on a Varian Workstation.

\section{Results and Discussion}

\section{Surface modification}

Montmorillonite K10 and silica gel have large, highly reactive surface areas rich in $\mathrm{OH}$ groups, which facilitate their modification. For this reason, we modified the surface of the clay and silica gel by reaction between the $\mathrm{OH}$ groups on these supports and aminopropyltriethoxysilane (Mont1 and Sil1) or $N$-(6-aminohexyl)-3-aminopropyl (Mont2 and Sil2), as seen in Figure 1, routes a and b, respectively. Upon functionalization, these supports proved to be excellent matrices for the immobilization of MePs containing good leaving groups, such as the para-fluoro atoms on the mesophenyl rings of the $\mathrm{FeP}$ and $\mathrm{MnP}$ employed in this work, which react with aminosubstituents through an aromatic nucleophilic substitution reaction (Figure 2).

Infrared (IR) spectroscopy is a simple method for detection of functional groups on the support, so it is often employed to provide evidence of surface modification in inorganic matrices. $\mathrm{H}^{+}$-K10 modification with 3-aminopropyltriethoxysilane, Mont1 (Figure 1, route a), results in the appearance of a band at $2927 \mathrm{~cm}^{-1}$ in the IR spectrum of the support, which is typical of the $\mathrm{C}-\mathrm{H}$ stretch of the propyl chain. A band at $1622 \mathrm{~cm}^{-1}$ characteristic of N-H asymmetric angular deformation ${ }^{19}$ also appears, thus confirming that the functionalization reaction really occurred. The nitrogen content from $\mathrm{CHN}$ analysis (C $4.60 \%, \mathrm{H} 1.84 \%, \mathrm{~N} 1.55 \%)$ gives an amine loading of $1.1 \mathrm{mmol} \mathrm{g}^{-1}$.

Reaction of $\mathrm{H}^{+}-\mathrm{K} 10$ or silica gel with 3-chloropropyltriethoxysilane (Figure 1, route b) leads to a decrease in the intensity of the band at $975 \mathrm{~cm}^{-1}$, due to the isolated Si-OH groups, in the IR spectrum of the starting supports. ${ }^{19}$ There is concomitant appearance of three bands at 2800, 2950 and $700 \mathrm{~cm}^{-1}$. The first two bands are assigned to the $\mathrm{C}-\mathrm{H}$ stretch of the propyl chain, while the third is typical of $\mathrm{C}-\mathrm{Cl}$ stretch. The solids generated from the reaction between the 3-chloropropyl-montmorillonite or 3-chloropropyl silica and 1,6-diaminohexane display a decreased band at $695 \mathrm{~cm}^{-1}$, followed by the appearance of two new bands at 3300 and $1500 \mathrm{~cm}^{-1}$, characteristic of $\mathrm{N}-\mathrm{H}$ groups. This confirms that the supports Mont2 and Sil2 were obtained. The nitrogen content from $\mathrm{CHN}$ analysis (C 6.88\%, H 2.40\%, N 1.38\%) gives amine loadings of $0.5 \mathrm{mmol} \mathrm{g}^{-1}$ and $1.25 \mathrm{mmol} \mathrm{g}^{-1}$, for Mont2 and Sil2, respectively.

\section{Covalent binding of the MePs to the aminated supports}

The catalysts chosen for covalent immobilization on the functionalized solids obtained in this work were the $2^{\text {nd }}$ generation metalloporphyrins (MePs) $[5,10,15,20$ tetrakis(pentafluorophenyl)porphyrin iron(III)] chloride, FeP, and [5,10,15,20-tetrakis(pentafluorophenyl)porphyrin manganese(III)] chloride, MnP. They were chosen because their corresponding free-base porphyrin is available commercially; these $2^{\text {nd }}$ generation MePs bear electronegative substituents on the meso-aryl rings, which increase the electrophilicity of the catalytic species and prevent catalyst autoxidative destruction; the para-fluoro substituents in these MePs act as good leaving groups, thus favoring nucleophilic substitution reactions. Furthermore, literature reports give evidence of the efficiency of these 


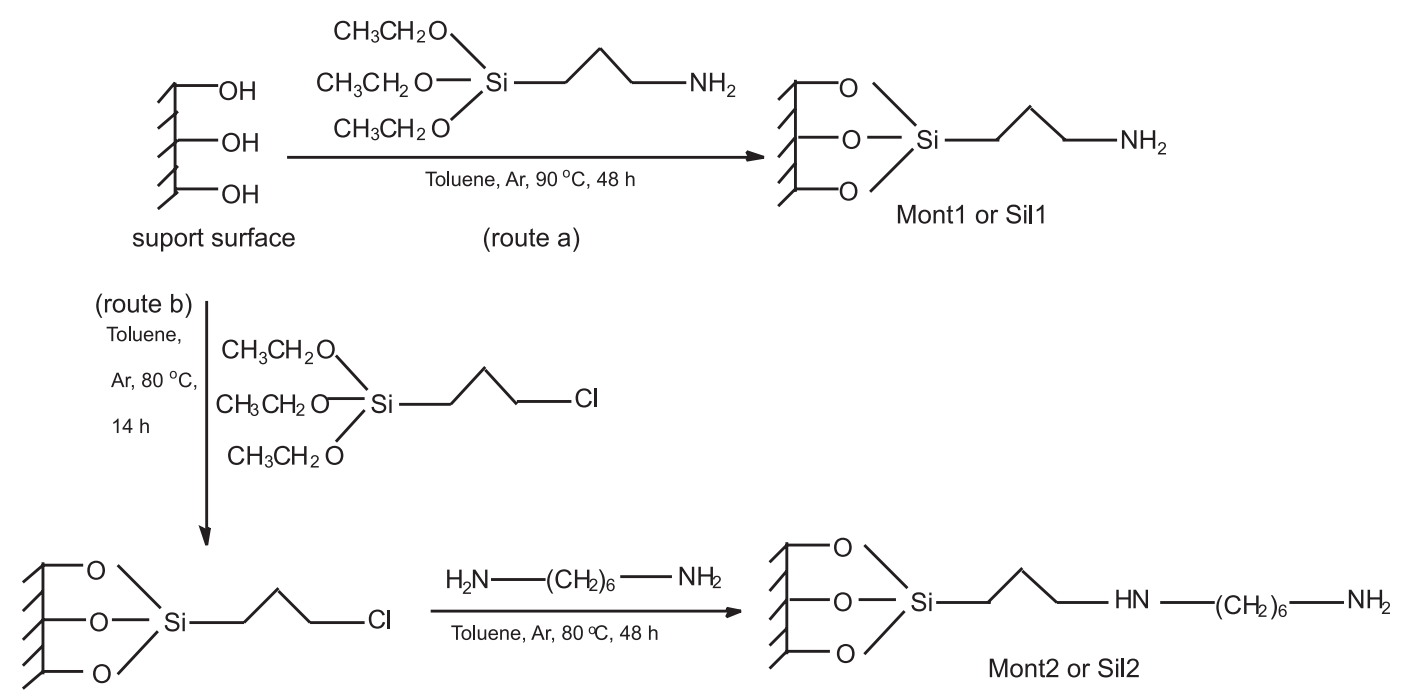

Figure 1. Modification of the surface of the solid supports, silica gel and montmorillonite-K10, by covalent binding of amino groups. Route a: modification with 3-aminopropyltriethoxysilane (Mont1 and Sil1). Route b: modification with 3-chloropropyltriethoxysilane, followed by reaction with 1,6-diaminohexane (Mont2 and Sil2).

catalysts and consider them good cytochrome P450 biomimetic models, which allows for a comparative evaluation of our results. ${ }^{18,20-22}$

The supported catalysts were obtained through the aromatic nucleophilic substitution reaction between the $\mathrm{NH}_{2}$ functional groups on the surface of the support and the para-fluoro atoms on the pentafluorophenyl substituent in the MePs (Figure 2).

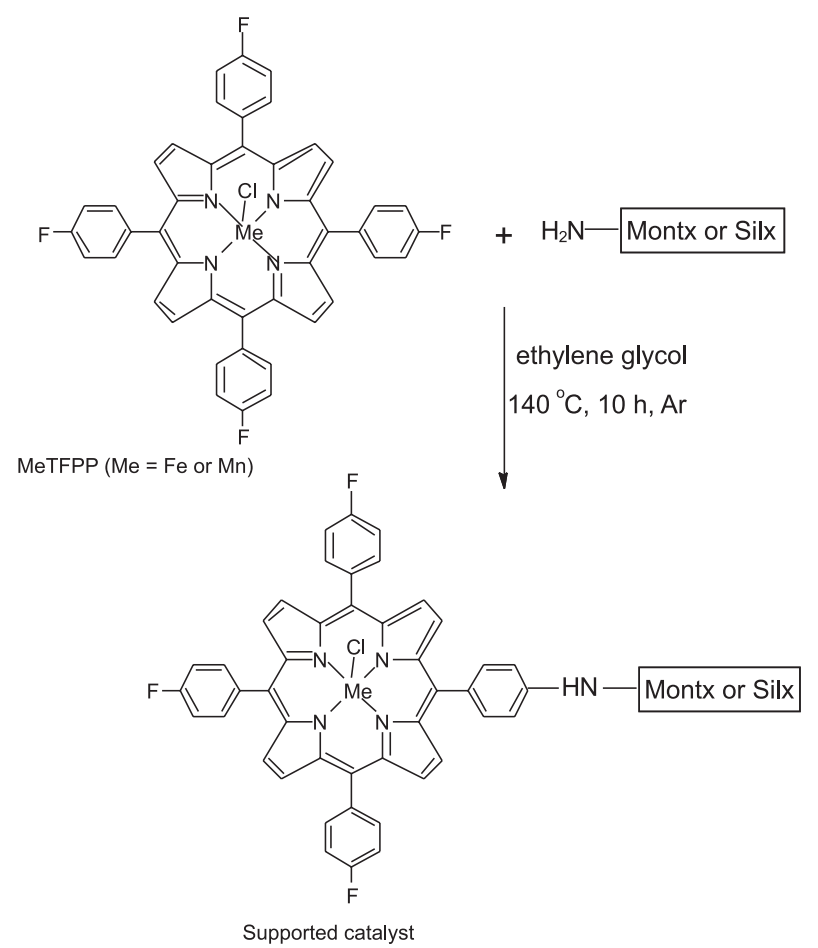

Figure 2. Anchoring of the MePs, where $\mathrm{Me}=\mathrm{Mn}$ or $\mathrm{Fe}$ on aminofunctionalized supports, by covalent binding.
The anchoring of the MePs was monitored by UVVis spectroscopy analysis of the reaction mixture, which displayed a decreased Soret band at $412 \mathrm{~nm}$ and $456 \mathrm{~nm}$ in the cases of $\mathrm{FeP}$ and $\mathrm{MnP}$, respectively. This shows that most of the MeP reacted with or adsorbed onto the support. After filtration, the adsorbed MeP was Soxhletextracted with dichloromethane for $24 \mathrm{~h}$, and then methanol for additional $24 \mathrm{~h}$. MeP loading on each support was indirectly determined by measuring the concentration of the complex in the combined extracts. The results are shown in Table 1. Data concerning previous characterization of these materials are also presented, as well as absorption wavelengths of the MePs Soret bands both in solution and anchored on the different supports. The spectra of the supported MePs were obtained from a suspension of the solid catalyst in $\mathrm{CCl}_{4}$.

All the solid catalysts display the typical Soret band of the parent homogeneous MeP (Table 1), which shows that the MeP structure is maintained upon immobilization. In the case of FeSilX and FeMontX, the Soret band is red-shifted $(8 \mathrm{~nm})$ compared with the parent $\mathrm{FeP}$ in $\mathrm{CCl}_{4}(412 \mathrm{~nm}$, Table 1). This shift toward longer wavelengths is probably due to porphyrin ring distortion upon immobilization on the support, ${ }^{23}$ as previously observed for similar systems ${ }^{7}$ and confirmed by the EPR spectra of these solids.

EPR was employed as an attempt to characterize the supported MePs in terms of the presence of the support, ring symmetry and central metal ion oxidation state. The EPR spectra of FeSil1 and FeSil2 (Figure 3) display signals in $g=6.0, g=4.3$ and $g=2.0$, typical of high-spin iron(III) species ( $\mathrm{S}=5 / 2, \mathrm{~g}=6.0$ and $\mathrm{g}=2.0$ ) and high-spin iron(III) species with rhombic distortion $(\mathrm{g}=4.3)$. The 
Table 1. Surface area $(\mathrm{S})$, amount of $\mathrm{NH}_{2}\left(\mathrm{n}_{\mathrm{a}}\right)$ on the support, amount of immobilized MePs on the aminofunctionalized supports $\left(\mathrm{n}_{\mathrm{b}}\right)$, and absorption band maximum $(\lambda$, Soret)

\begin{tabular}{lcccc}
\hline Catalyst & $\begin{array}{c}\mathrm{S} / \\
\left(\mathrm{m}^{2} \mathrm{~g}^{-1}\right)\end{array}$ & $\begin{array}{c}\mathrm{n}_{\mathrm{a}} / \\
\left(\mathrm{mmol} \mathrm{g}^{-1}\right)\end{array}$ & $\begin{array}{c}\mathrm{n}_{\mathrm{b}} / \\
\left(\mu \mathrm{mol} \mathrm{g}^{-1}\right)\end{array}$ & $\lambda / \mathrm{nm}$ \\
\hline FeP & - & - & - & 412 \\
MnP & - & - & - & 478 \\
FeMont1 & 249 & 1.1 & 8.3 & 418 \\
FeMont2 & 258 & 0.5 & 3.3 & 420 \\
MnMont1 & 231 & 1.1 & 2.2 & 476 \\
MnMont2 & 52 & 0.5 & 940 & 476 \\
FeSil1 & 82 & 1.5 & 1000 & 420 \\
FeSil2 & 69 & 1.25 & 248 & 420 \\
MnSil1 & 99 & 1.5 & 750 & 478 \\
MnSil2 & 43 & 1.25 & 800 & 478 \\
\hline
\end{tabular}

presence of this intense rhombic signal confirms that the $\mathrm{FeP}$ is distorted due to the proximity of the support, which probably results from the axial coordination of the central metal ion to the $\mathrm{NH}_{2}$ groups on the support. The intensities of the characteristic high-spin iron(III) signals in $\mathrm{g}=6.0$ and $\mathrm{g}=2.0$ are low in the EPR spectra of FeMont1 and FeMont2 (Figure 3). A very intense signal in $\mathrm{g}=4.3$ indicates that the presence of high-spin iron(III) species with rhombic distortion is predominant in these solids.

The Soret band in the UV-Vis spectra of the immobilized MnPs is not shifted (Table 1), indicating that the porphyrin ring structure does not change upon immobilization. The EPR spectra of the solid catalysts containing MnP (Figure 4) display signals around $g=2$. This signal consists of 6 lines, which is typical of manganese(II) species $(\mathrm{S}=5 / 2)$. The multiplet in $\mathrm{g} c a$. 2 separated by approximately 90 gauss is due to a hyperfine interaction with the nuclear spin of the Mn atom. Manganese(III) ions are EPR silent. The partial reduction of the manganese(III) ions verified by EPR is due to the coordination of the porphyrin central Mn ion to free amino groups on the support. The spectra of the supported MnPs also display a signal in $\mathrm{g}=4.2$, due to high-spin iron(III) species with rhombic symmetry. This signal was also present in the spectrum of montmorillonite containing no MeP, so it must be due to iron impurities present in the clay, which persisted throughout the immobilization process.

The XRD patterns of FeP-K10 and $\mathrm{H}^{+}-\mathrm{K} 10$ (for comparison) were recorded at $2 \theta$ values ranging from $5^{\circ}$ to $50^{\circ}$. Analysis of the diffractograms reveals that FeP-K10 is structurally similar to $\mathrm{H}^{+}-\mathrm{K} 10$, which indicates that the FeP is not intercalated between the layers. Since the $\mathrm{FeP}$ is strongly attached to the solid, as confirmed by the absence of FeP in the washing extracts obtained after FeP

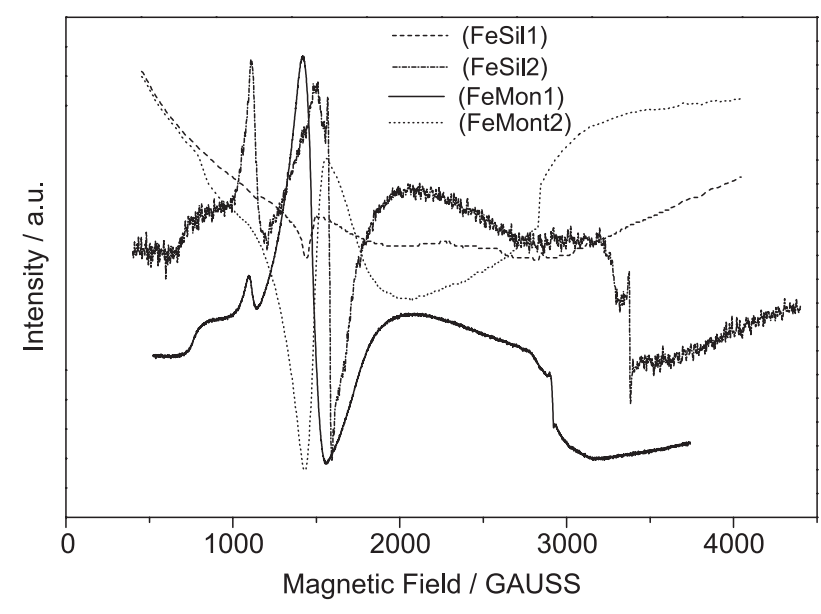

Figure 3. EPR spectra of FeP supported on Mont and Sil; T ca. $77 \mathrm{~K}$, $v=9 \mathrm{GHz}$, gain $=1000$.

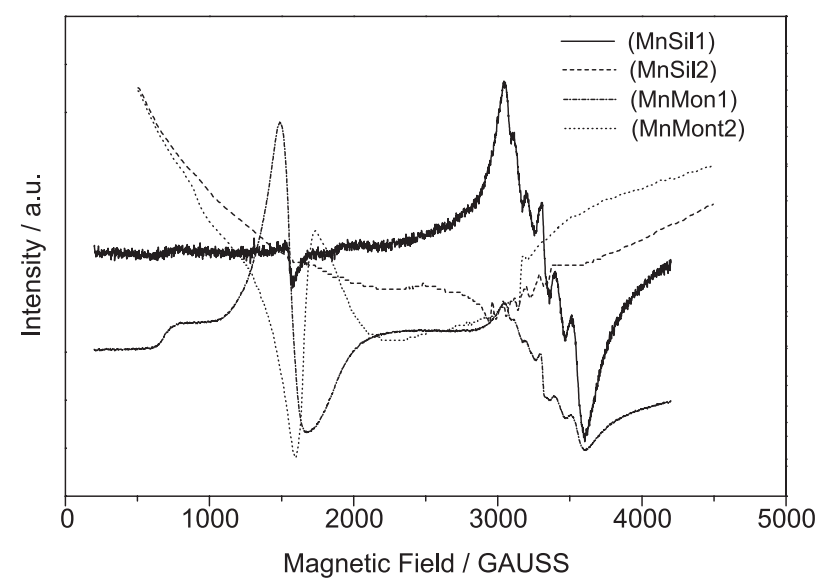

Figure 4. EPR spectra of MnP supported on Mont and Sil; T ca.77 K, $v=9 \mathrm{GHz}$, gain $=1000$.

immobilization, one can conclude that the $\mathrm{FeP}$ is present in broken bonds at the edges or defects of the crystal surface, as observed in reference 23 and others ${ }^{8,9,24}$ for similar systems.

The surface areas of the supported catalysts were determined by BET techniques. The data are presented in Table 1. The low areas of MnMont2, MnSil1, FeSil1, MnSil2 and FeSil2 can be attributed to the high level of catalyst immobilization on the support, since the amino groups and the catalyst itself can block the access of gaseous nitrogen to the surface.

\section{Catalytic results}

(Z)-Cyclooctene, cyclohexane and styrene were used as substrates to investigate the potential application of the supported MePs as catalysts for hydrocarbon oxidation. Analysis of the oxidation products from structurally different substrates provided information on the reactivity, 
selectivity, and oxidation states and structures of the catalytically active intermediate species.

A blank reaction using the solid matrix with no anchored $\mathrm{MeP}$ was carried out for all the systems. No products were detected in the absence of catalyst.

\section{Oxidations with iodosylbenzene}

Catalyst efficiency and stability were first investigated in the epoxidation of $(Z)$-cyclooctene by PhIO. Both this substrate and the oxidant have been largely employed in diagnostic reactions to evaluate the catalytic potential of novel systems, so they allow comparison with various other systems studied by our group or described in the literature. 1,7,18,21,25,26 The reaction products were analyzed by gas chromatography, and the yields are based on the oxidant. Results are presented in Table 2.

Table 2. Product yields from the oxidation of $(Z)$-cyclooctene by $\mathrm{PhIO}$ catalyzed by homogeneous and supported MePs

\begin{tabular}{|c|c|c|c|c|c|}
\hline \multirow{2}{*}{$\begin{array}{l}\text { Reaction } \\
\text { number }\end{array}$} & \multirow{2}{*}{ Catalyst } & \multirow{2}{*}{$\begin{array}{l}\text { Carbon chain } \\
\text { length }^{\mathrm{a}}\end{array}$} & \multicolumn{3}{|c|}{ Cyclooctenoxide yield / $(\%)$} \\
\hline & & & $\mathrm{A}^{(\mathrm{c})}$ & $\mathrm{B}^{(\mathrm{c})}$ & $\mathrm{C}^{(\mathrm{c})}$ \\
\hline 1 & $\mathrm{FeP}$ & - & 96 & - & 90 \\
\hline 2 & $\mathrm{MnP}$ & - & 94 & - & 100 \\
\hline 3 & FeMont1 & 4 & 85 & 90 & 55 \\
\hline 4 & MnMont1 & 4 & 58 & 70 & 75 \\
\hline 5 & FeMont2 & 11 & 40 & 70 & - \\
\hline 6 & MnMont2 & 11 & 30 & 42 & 45 \\
\hline 7 & FeSill & 4 & 85 & 95 & - \\
\hline 8 & MnSil1 & 4 & 48 & & \\
\hline 9 & FeSil2 & 11 & 65 & 92 & - \\
\hline 10 & MnSil2 & 11 & 50 & 60 & 62 \\
\hline
\end{tabular}

${ }^{a}$ number of carbon atoms on the chain binding the MeP to the

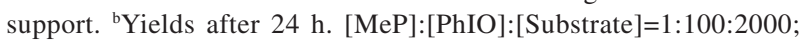
$[\mathrm{MeP}]=10^{-7} \mathrm{~mol} \mathrm{~L}^{-1}$ in DCE. ${ }^{\text {(c) }} \mathrm{A}$ - catalyst before acetylation; $\mathrm{B}$ - catalyst after acetylation; $\mathrm{C}$ - reaction performed in the presence of imidazole.

Most of the supported MePs are very efficient catalysts for $(Z)$-cyclooctene epoxidation by PhIO. The results allowed us to evaluate some of the parameters that influence catalyst efficiency: the effect of the support, the distance between the MeP and the support surface, bis-coordination of the free amino groups on the support to the central metal ion of the MeP, and the effect of metal type in the porphyrin macrocycle.

Acetylation of the $\mathrm{NH}_{2}$ group of the support (Table 2) brings up a significant increase in the efficiency of all the catalysts. The free amino groups on the matrix affect the MeP activity through one or more of the following effects: (i) they axially bis-coordinate to the metal ion, blocking the catalytic site; (ii) they act as a competitive substrate, thus behaving as an anti-oxidant; (iii) they induce reduction of the metal ion, thereby hindering the formation of the high-valence catalytically active species, generally the oxo-metal(IV) porphyrin $\pi$-cation radical. ${ }^{27,28}$ All these effects are minimized or even diminished by acetylation of the free $\mathrm{NH}_{2}$ groups.

Surfaces containing $\mathrm{NH}_{2}$ groups also influence the catalytic reaction by modifying support polarity. This affects reaction rates and interferes with substrate, intermediate and product diffusion between the solution and the solid phase., ${ }^{7,29}$

Catalysts containing the $\mathrm{FeP}$ are more efficient for (Z)-cyclooctene oxidation than those containing the MnP (reactions 3, 5, 7 and 9, Table 2). These results differ from those reported in the literature, which generally state that manganese(III) porphyrins are more efficient than iron(III) porphyrins, although the former are less selective. ${ }^{17,28,30}$ The lower yields obtained with the materials containing MnP may be attributed to the presence of manganese(II) in the catalyst, generated from the axial bis-coordination of $\mathrm{NH}_{2}$ groups on the support, as revealed by EPR (Figure 4). The fact that $\mathrm{Mn}$ is reduced should make the formation of the high-valence catalytically active species $\mathrm{Mn}^{\mathrm{V}}(\mathrm{O}) \mathrm{P}$ more difficult, and should lead to the formation of the less reactive species $\mathrm{Mn}^{\mathrm{IV}}(\mathrm{O}) \mathrm{P}{ }^{31}$ Although acetylation of the free amino groups on the support leads to an increase in epoxide yields in the case of the supported MnP catalysts, results are still below those achieved with the supported FeP. This can be attributed to the incomplete acetylation of the $\mathrm{NH}_{2}$ groups or to the presence of manganese(II) in the support even after the protection with acetyl groups (Figure 4).

The presence of nitrogen bases in the oxidation reactions catalyzed by iron(III) porphyrins and manganese(III) porphyrins affects the reaction rate, product yields, and chemo and regioselectivities. This is because nitrogen bases can coordinate to the central metal ion in the position trans to the $\mathrm{M}=\mathrm{O}$ bond, thus favoring the formation of the active catalytic species. In this way, the nitrogen base is said to act as a cocatalyst. ${ }^{28,32,33}$ The axial ligand effect is generally more pronounced in the reactions catalyzed by manganese(III) porphyrins. However, in the systems studied in this work (reactions 4 and 6, Table 2), there is virtually no change in epoxide yields upon imidazole addition. This confirms that the presence of manganese(II) species in the supported catalysts is the factor responsible for the lower yields achieved with the immobilized MnP. As for FeP, lower epoxide yields are obtained in the presence of imidazole. This is because the iron(III) ion tends to form hexacoordinate complexes, so imidazole coordinates to the two axial positions of the Fe ion in the FeP, thus blocking 
the oxidant and substrate binding sites and leading to loss of catalytic efficiency (FeMont1, reaction 3, Table 2). Furthermore, imidazole can compete with the substrate for the oxidant, generating the corresponding $N$-oxide. ${ }^{34,35}$

It has been previously reported that supported catalysts display different catalytic activities depending on the length of the carbon chain attaching them to the solid matrix. ${ }^{7}$ On the whole, very short chains are not favorable because they keep the catalyst too close to the solid surface, which results in larger steric hindrance to the approach of the reactants. Another drawback is that the catalyst is too close to the polar surface of the support, which does not favor the approach of non-polar substrates. On the other hand, very long chains are too flexible, thus favoring central metal ion bis-coordination to the free amino groups on the support.

In the case of the clay montmorillonite K10 (Mont1 and Mont2), better yields are achieved with the solid containing a 4-carbon chain (Mont1) (reactions 3 and 4, Table 2). A comparison between FeSil1 (4 atoms) and FeSil2 (11 atoms) also shows that the shorter chain leads to a more efficient catalyst. However, the catalytic activities of FeSil1 and FeSil2 are virtually the same after acetylation of the free $\mathrm{NH}_{2}$ groups (reactions 7 and 9, Table 2), indicating that the lower efficiency observed for FeSil2 prior to acetylation is really due to the unfavorable effects of the $\mathrm{NH}_{2}$ substituents.

To investigate whether there is MeP leaching from the support throughout substrate oxidation, at the end of the reaction the solid catalyst was filtered, and the supernatant was employed in a further oxidation reaction under the same conditions. No product formation was observed, confirming that the catalysis is truly heterogeneous.

That the MeP is not destroyed during the catalysis was confirmed by recycling one of the most efficient catalytic systems, FeSil1. In these experiments, FeSil1 was separated at the end of the oxidation reaction by filtration, washed with dichloromethane and methanol, and reused in the same conditions. The results (Figure 5) show that the catalytic activity is maintained $(85 \%)$ up to the $3^{\text {rd }}$ recycling, giving evidence of the catalyst's stability. After the third consecutive reaction, the product yield decreases significantly. This can be explained by the difficulty in filtering the solid, which leads to solid catalyst loss during the washing process and makes reproducibility of the reaction conditions difficult.

No degradation of the FeSill system is observed in consecutive reactions up to three additions of oxidant (catalyst/oxidant ratio $=1: 300$, added at $8 \mathrm{~h}$ intervals). This leads to a total turnover of 640 , demonstrating that the system is highly stable.

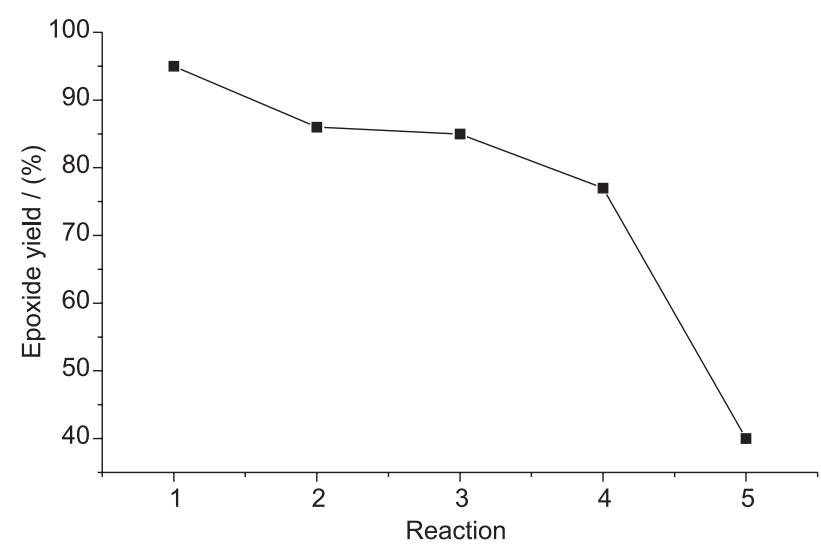

Figure 5. Percentage yield (based on PhIO after $24 \mathrm{~h}$ ) generated from (Z)-cyclooctene oxidation by $\mathrm{PhIO}$ in recycling reactions using the supported catalyst FeSil1.

The catalytic activity of these systems was also evaluated in the oxidation of cyclohexane. As shown in Table 3, the supported catalysts 3, 4, 7, 8 and 9 lead to good product yields and are highly selective for the alcohol, compared with the parent homogeneous systems and other similar heterogeneous systems described in the literature..$^{2,7,8,17,25}$ The most efficient catalysts are FeSil1, FeMont1 and MnMont1 in the presence of imidazole.

Table 3. Product yields from the cyclohexane oxidation by PhIO catalyzed by homogeneous and supported MePs

\begin{tabular}{lccccccc}
\hline \multirow{2}{*}{$\begin{array}{l}\text { Reaction } \\
\text { number }\end{array}$} & Support & \multicolumn{7}{c}{ Cyclohexanol } & \multicolumn{2}{c}{ Cyclohexanone } \\
& & A & B & C & A & B & C \\
\hline 1 & FeP & 93 & - & 65 & - & - & - \\
2 & MnP & 10 & - & 60 & - & - & - \\
3 & FeMont1 & 29 & 45 & - & 1 & 2 & - \\
4 & MnMont1 & 10 & 35 & 40 & 1 & 3 & 2 \\
5 & FeMont2 & 0 & 3 & - & 0 & 0 & - \\
6 & MnMont2 & 5 & 0 & 6 & 0 & 0 & 0 \\
7 & FeSil1 & 15 & 38 & - & 0 & 0 & - \\
8 & MnSil1 & 14 & & & 7 & & \\
9 & FeSil2 & 8 & 20 & - & 0 & 3 & - \\
10 & MnSil2 & 5 & 18 & 30 & 1 & - & 2 \\
\hline
\end{tabular}

(A) catalyst before acetylation; (B) catalyst after acetylation; (C) reaction performed in the presence of imidazole; *yields after $24 \mathrm{~h} .[\mathrm{MeP}] /[\mathrm{PhIO}] /$ [Substrate $]=1: 100: 2000 ;[\mathrm{MeP}]=10^{-7} \mathrm{~mol} \mathrm{~L}^{-1}$ in DCE.

Because cyclohexane is little reactive, the use of a cocatalyst is crucial to enhancing the catalytic activity of manganese(III) porphyrins in solution, as shown in Table 3. Relatively higher product yields are obtained in the presence of imidazole, with selective formation of cyclohexanol (reaction 2, Table 3). In the case of the solid catalysts, though, the increase in product yields in the presence of the 
cocatalyst is not significant (reactions 4, 6 and 10, Table 3). This is probably because manganese(II) species are present in these systems, as discussed previously.

As observed and discussed in the case of $(Z)$-cyclooctene oxidation, supports containing a 4-carbon chain, like Mont1 and Sil1, also lead to higher cyclohexanol yields.

A large difference between the catalytic activities of MePs supported on Mont1 and Mont2 (Table 3, reactions 3 and 5, 4 and 6) is observed. The low efficiency of the catalysts immobilized on Mont 2 can be attributed to the longer carbon chain in this material and to the possibility of these 'arms' being located in the interlamellar space, which should hinder the approach of the reactants. Compared with (Z)-cyclooctene, such effects are even more pronounced when cyclohexane is employed as the substrate because it is a more inert molecule.

Styrene is a terminal alkene that is very frequently employed as substrate in studies involving MeP systems ${ }^{36,37,38}$ and analogous complexes. ${ }^{39,40}$ The easy carbon-carbon bond rotation in the reaction intermediate is the greatest difficulty encountered during the enantioselective epoxidation of this terminal alkene. The products from MeP-catalyzed styrene oxidation by $\mathrm{PhIO}$ or $\mathrm{H}_{2} \mathrm{O}_{2}$ are styrene oxide, benzaldehyde and phenylacetaldehyde..$^{36,41,42}$

Styrene epoxide is formed via the classic mechanism involving the active intermediate oxo-ferryl porphyrin $\pi$-cation radical. Benzaldehyde formation has been reported to occur through a different route. ${ }^{42-45}$ It probably originates from a slow aerobic oxidation that requires the presence of both the MeP and the oxidant. This mechanism has been attributed to an autoxidation, probably involving a reactive intermediate cation radical and molecular oxygen (from the atmosphere), which triggers a free-radical chain process (Figure 6). Therefore, there is competition between autoxidation (with formation of benzaldehyde) and the generation of styrene epoxide.

Phenylacetaldehyde can be formed from the rearrangement of the intermediate (route b, Figure 7), which competes with epoxide formation (route a, Figure 7). ${ }^{42}$

The results obtained from styrene oxidation by $\mathrm{PhIO}$ catalyzed by the various supported FePs and MnPs are shown in Table 4. As in the case of (Z)-cyclooctene, the supported FePs are better catalysts than the corresponding MnPs, even when the latter are in the presence of a cocatalyst.

MnSil2 is a very efficient catalyst compared with the other MnP systems, ${ }^{17,25}$ leading to an epoxide yield of 55\% (reaction 6, Table 4), similar to that obtained for the MnP in homogeneous solution (62\%, reaction 2, Table 4). However, the supported system is much more selective, leading to a higher epoxide/benzaldehyde ratio (5.5) than that obtained in solution (2.5) or with other supported catalysts. ${ }^{7}$

MePs immobilized on Mont 1 and 2 give very low epoxide/benzaldehyde ratios (reactions 3, 4, 5 and 6, Table 4). This is probably due to the presence of a larger amount of residual molecular oxygen in these systems, once

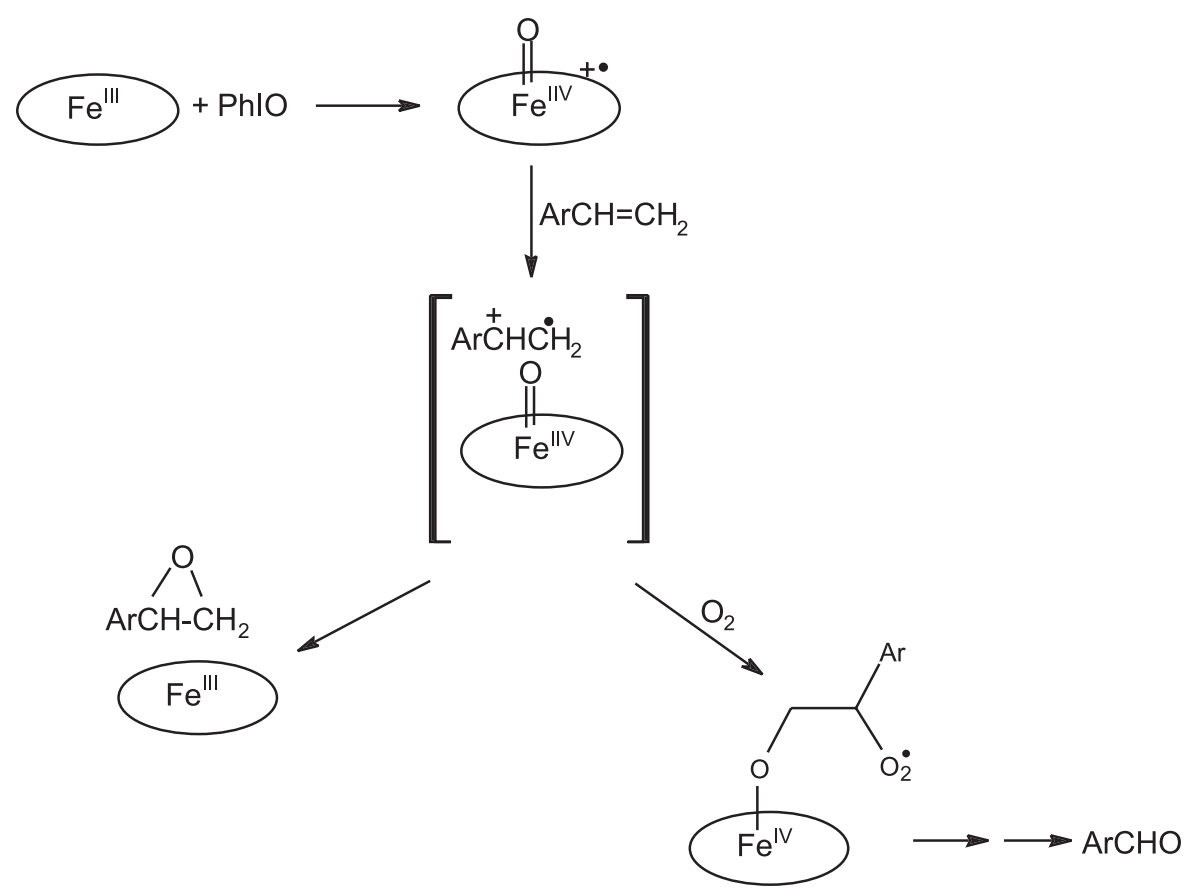

Figure 6. Possible route for autoxidation and consequent generation of benzaldehyde in parallel with epoxidation during styrene oxidation by the FeP/PhIO system, as adapted from reference 43 . $\bigcirc$ represents the porphyrin ring. 


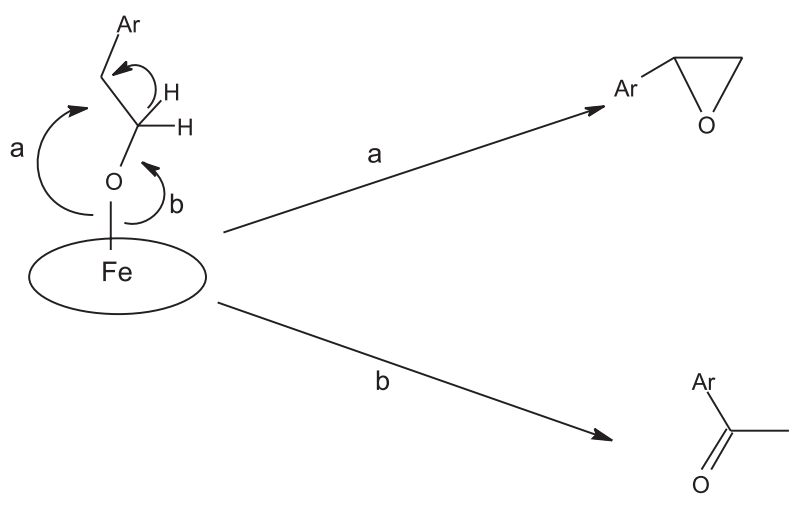

Figure 7. Mechanism of phenylacetaldehyde formation, adapted from reference 40

Table 4. Product yields from styrene oxidation by $\mathrm{PhIO}$ catalyzed by homogeneous and supported MePs, under argon atmosphere

\begin{tabular}{lcccc}
\hline $\begin{array}{l}\text { Reaction } \\
\text { number }\end{array}$ & Catalyst & \multicolumn{3}{c}{$\begin{array}{c}\text { Yield / }(\%)^{* *} \\
\text { Epoxide }\end{array}$} \\
\hline 1 & FeP & 80 & 18 & 5 \\
2 & MnP* & 62 & 25 & 10 \\
3 & FeMont1 & 52 & 25 & 3 \\
4 & FeMont2 & 20 & 30 & 5 \\
5 & MnMont $1^{*}$ & 37 & 13 & $<5$ \\
6 & MnMont2* & 25 & 10 & 8 \\
9 & FeSil1 & 73 & 22 & 7 \\
10 & MnSil1 & 50 & 0 & 0 \\
7 & FeSil2 & 80 & 5 & 0 \\
8 & MnSil2* & 55 & 10 & 0 \\
\hline
\end{tabular}

*Reactions with $\mathrm{Mn} / \mathrm{Im}$ molar ratio $=1: 30$; **reaction with solid catalyst after acetylation; yields after $24 \mathrm{~h} ;[\mathrm{MeP}] /[\mathrm{PhIO}] /[$ Substrate] $=1: 100: 2000$;

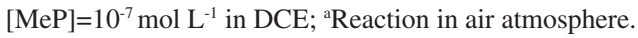

it is difficult to eliminate this gas from the clay layers. The presence of dioxygen favors the free radical mechanism that results in benzaldehyde formation.

In some reactions there is a generation of a small quantity of phenylacetaldehyde $(<10 \%)$, which is usual in systems involving MePs. This product is formed via rearrangement of the intermediate oxo-carbonium, where hydrogen atom migration competes, to a small extent, with the ring closure that leads to epoxide formation (Figure 7). In this mechanism, the equilibrium involving the binding of the olefin to the MeP is sensitive to steric effects. ${ }^{46}$ Because of the fact that in the present work the MeP is immobilized on the support, the steric effect of the matrix also influences the mechanism of oxygen atom transfer to the olefin. The steric hindrance provided by the support disfavors the rearrangement that leads to phenylacetaldehyde formation, accounting for the lower yields of this aldehyde in the case of the immobilized systems (Table 4).

\section{Oxidation with hydrogen peroxide}

The literature contains several reports on the advantages of the use of hydrogen peroxide in redox reactions, including the fact that $\mathrm{H}_{2} \mathrm{O}_{2}$ is a clean oxidant. However, the catalytic activity of MePs in the presence of hydrogen peroxide is limited due to the fact that $\mathrm{H}_{2} \mathrm{O}_{2}$ tends to undergo disproportionation into $\mathrm{H}_{2} \mathrm{O}$ and $\mathrm{O}_{2}$, which is catalyzed by the MeP in the same way that is catalyzed by catalase in vivo. An additional difficulty with supported MePs is the fact that the inorganic matrix can lead to peroxide dismutation.

Despite the above-mentioned limitations, product yields from $(Z)$-cyclooctene, cyclohexane and styrene oxidation by $\mathrm{H}_{2} \mathrm{O}_{2}$ catalyzed by the supported MePs (Tables 5, 6 and 7) are similar to or even higher than those reported in the literature. ${ }^{17,25,37}$

Table 5. Product yields from ( $Z$ )-cyclooctene oxidation by $\mathrm{H}_{2} \mathrm{O}_{2}$ catalyzed by homogeneous and supported MePs

\begin{tabular}{lccc}
\hline \multirow{2}{*}{ Reaction number } & Catalyst & \multicolumn{2}{c}{ Epoxide yield / (\%)* } \\
& & A & B \\
\hline 1 & FeP & 25 & - \\
2 & FeP** & 10 & - \\
3 & MnP & 10 & - \\
4 & MnP** & 65 & - \\
5 & FeMont1 & 29 & 45 \\
6 & MnMont1** & 10 & 40 \\
7 & FeMont2 & 15 & 20 \\
8 & MnMont2** & 5 & 6 \\
9 & FeSil1 & 15 & 38 \\
10 & MnSil1** & 5 & 25 \\
12 & FeSil2 & 8 & 20 \\
13 & MnSil2** & 5 & 30 \\
\hline
\end{tabular}

(A) catalyst prior to acetylation; (B) catalyst after acetylation. *Yields after $24 \mathrm{~h}$. $[\mathrm{MeP}] /\left[\mathrm{H}_{2} \mathrm{O}_{2}\right] /[$ Substrate $]=1: 100: 2000 ;[\mathrm{MeP}]=10^{-7} \mathrm{~mol} \mathrm{~L}^{-1}$ in DCE; **reaction with $[\mathrm{MnP}] /[\mathrm{Im}]=1: 30$.

The most efficient catalysts for $(Z)$-cyclooctene oxidation are FeSil1, FeMont1 and MnMont1 (Table 5). These systems are even more efficient than the parent MePs in homogeneous solution. The increase in the catalytic activity in the case of the immobilized systems is probably due to the acidity of the support, which favors oxygen protonation and heterolytic cleavage of the peroxide O-O bond, thus leading to the formation of the active species oxo-ferryl porphyrin $\pi$-cation radical.

The presence of a cocatalyst and the acetylation of the support are essential for higher product yields in the case of the MnP systems. Relatively high yields are obtained with $\mathrm{MnP}$ and MnSil2 (reactions 4 and 12, respectively, Table 5). Imidazole acts in two ways: it favors the generation of the catalytic species and functions as a basic catalyst in the 
heterolytic cleavage of the peroxide $\mathrm{O}-\mathrm{O}$ bond, leading to the formation of $\mathrm{Mn}^{\mathrm{V}}(\mathrm{O}) \mathrm{P}$.

Table 6. Product yields from cyclohexane oxidation by $\mathrm{H}_{2} \mathrm{O}_{2}$ catalyzed by homogeneous and supported MePs

\begin{tabular}{lcc}
\hline Catalyst & \multicolumn{2}{c}{ Cyclohexanol Yield / $\%)^{*}$} \\
\hline FeP (solution) & A & B \\
FeP** & 5 & - \\
MnP (solution) & 8 & - \\
MnP** & 0 & - \\
FeMont1 & 25 & - \\
MnMont1** & 12 & 16 \\
FeMont2 & 0 & $<5$ \\
MnMont2** & 5 & 5 \\
FeSil1 & 0 & 0 \\
MnSil1 & 0 & $<5$ \\
FeSil2 & 2 & 10 \\
MnSil2** & 10 & 13 \\
\hline
\end{tabular}

(A) catalyst prior to acetylation; (B) catalyst after acetylation. *Yields after $24 \mathrm{~h}$. $[\mathrm{MeP}] /\left[\mathrm{H}_{2} \mathrm{O}_{2}\right] /[$ Substrate $]=1: 100: 2000 ;[\mathrm{MeP}]=10^{-7} \mathrm{~mol} \mathrm{~L}^{-1}$ in $\mathrm{DCE}$; **reaction with $[\mathrm{MnP}] /[\mathrm{Im}]=1: 30$.

The supported MePs also catalyze cyclohexane oxidation by $\mathrm{H}_{2} \mathrm{O}_{2}$, as shown in Table 6. However, the supported MeP/ $\mathrm{H}_{2} \mathrm{O}_{2}$ systems are less efficient than other systems reported in the literature ${ }^{17,25}$ and the $\mathrm{MeP} / \mathrm{PhIO}$ systems described in this work. The inertness of cyclohexane, allied with the previously discussed limitations inherent to supported systems, may account for the lower yields.

As in the case of the supported MeP/PhIO systems, the best catalysts for styrene oxidation by $\mathrm{H}_{2} \mathrm{O}_{2}$ are FeMont1, FeSil2 and MnMont1 (Table 7). No phenylacetaldehyde formation

Table 7. Product yields from styrene oxidation by $\mathrm{H}_{2} \mathrm{O}_{2}$ catalyzed by homogeneous and supported MePs

\begin{tabular}{lcccc}
\hline \multirow{2}{*}{ Catalyst } & \multicolumn{4}{c}{ Yield / (\%)* } \\
& \multicolumn{2}{c}{ Epoxide } & \multicolumn{2}{c}{ Benzaldehyde } \\
& A & B & A & B \\
\hline FeP & 6 & - & 15 & - \\
MnP** & 25 & - & 10 & - \\
FeMont1 & 35 & 42 & 20 & 25 \\
MnMont1** & 20 & 25 & 10 & 13 \\
FeMont2 & 15 & 20 & 20 & 27 \\
MnMont2** & 5 & 8 & 0 & $<5$ \\
FeSil1 & 18 & 25 & $<5$ & 8 \\
MnSil1 & 6 & 10 & 0 & $<5$ \\
FeSil2 & 30 & 37 & 5 & 8 \\
MnSil2** & 8 & 12 & 0 & $<5$ \\
\hline (A)
\end{tabular}

(A) catalyst prior to acetylation; (B) catalyst after acetylation. *Yields after $24 \mathrm{~h}$. $[\mathrm{MeP}] /\left[\mathrm{H}_{2} \mathrm{O}_{2}\right] /[$ Substrate $]=1: 100: 2000 ;[\mathrm{MeP}]=10^{-7} \mathrm{~mol} \mathrm{~L}^{-1}$ in DCE; **reaction with $[\mathrm{MnP}] /[\mathrm{Im}]=1: 30$. is observed. Product yields and epoxide/benzaldehyde selectivities are much higher in the case of the supported catalysts compared with the homogeneous counterparts. Benzaldehyde is formed via a free radical mechanism, favored by the homolytic cleavage of the peroxide O-O bond, ${ }^{47}$ which seems to predominate in homogeneous systems, but not in heterogeneous ones. This is probably because the acidity of the support favors the heterolytic cleavage of the peroxo bond, as discussed above.

\section{Conclusions}

Aminofunctionalized supports have proven to be excellent matrices for metalloporphyrin immobilization via covalent bond. The SilX-immobilized metalloporphyrins are better catalysts for oxidation reactions than the corresponding MontX-supported metallocomplexes (lamellar), because the former support keeps the catalyst more available for interaction with the reagents. The length of the carbon chain binding the metalloporphyrin to the support is crucial to the catalytic activity. Chains containing four carbon atoms are more suitable for metalloporphyrin immobilization, since the metallocomplex is kept at a suitable distance from the support, thus minimizing steric and polarity effects from the matrix. Four-carbon chains are also advantageous because they maintain the catalyst in such a distance from the support that the catalytic site is not blocked by metal ion bis-coordination to the free amino ligands on the surface of the matrix. Protection of the free $\mathrm{NH}_{2}$ groups through acetylation is essential to prevent this coordination, and it leads to higher product yields. In the search for clean and commercially available oxidants, hydrogen peroxide is a promising candidate in the area of heterogeneous catalysis with metalloporphyrins, giving rise to more efficient systems than the corresponding homogeneous MePs. The most efficient catalysts investigated in this work will be used for drug oxidation, with a view to synthesizing drug metabolites.

\section{Acknowledgments}

We thank FAPESP, CAPES and CNPq for financial support. We also acknowledge Dr. Cynthia Maria de Campos Prado Manso for linguistic advice and Prof. Dr. Carlos F. Graeff for the EPR spectra.

\section{References}

1. Matachowski, L.; Pamin, K.; Połtowicz, J.; Serwicka, E. M.; Jones, W.; Mokaya, R.; Appl. Catal., A 2006, 313, 106. 
2. Huang, G.; Guo, C.;Tang, S.; J. Mol. Catal. A: Chem. 2007, $261,125$.

3. Serrano, D. P.; Aguado, J.; Vargas, C.; Appl. Catal., A 2008, 335, 172.

4. Zimowska, M.; Michalik-Zym, A.; Połtowicz, J.; Bazarnik, M.; Bahranowski, K.; Serwicka, E. M.; Catal. Today 2007, 124, 55 .

5. Nakagaki, S.; Wypych, F.; J. Colloid Interface Sci. 2007, 315, 142.

6. Lindsay Smith, J. R.; Metalloporphyrins in Catalytic Oxidations, Marcel Dekker Inc.: New York, 1994, p. 325.

7. Faria, A. L.; Airoldi, C.; Doro, F. G.; Fonseca, M. G.; Assis, M. D.; Appl. Catal., A 2004, 268, 217.

8. Nakagaki, S.; Machado, A. M.; Wypych, F.; Drechsel, S. M.; J. Colloid Interface Sci. 2002, 254, 158.

9. Barros, V. P.; Faria, A. L.; MacLeod, T. C. O.; Moraes, L. A. B.; Assis, M. D.; Int. Biodeterior. Biodegrad. 2008, 61, 337.

10. Dhakshinamoorthy, A.; Pitchumani, K.; Tetrahedron 2006, 62, 9911.

11. Pinnavaia, T. J.; Science 1983, 220, 4595.

12. Santos, P. S.; Ciência e Tecnologia de Argilas, Edgar Blucher: São Paulo, 1992.

13. Sharefkin, J. G.; Saltzman, H.; Org. Synth. 1963, 5, 660.

14. Sharefkin, J. G.; Saltzman, H.; Org. Synth. 1963, 5, 658.

15. Lucas, H.; Kennedy, E. R.; J. Org. Chem. 1955, 3, 484.

16. Adler, A. D.; Longo, F. R.; Kampas, F.; Kim, J.; J. Inorg. Nucl. Chem. 1970, 32, 2443.

17. Martinez-Lorente, M. A.; Battioni, P.; Kleemiss, W.; Bartoli, J. F.; Mansuy, D.; J. Mol. Catal. A: Chem. 1996, 113, 343.

18. Evans, S.; Lindsay Smith, J. R.; J. Chem. Soc., Perkin Trans. 2 2001, 174.

19. Silverstein, R. M.; Bassler, G. C.; Morrel, T. C.; Spectrometric Identification of Organic Compounds, $5^{\text {th }}$ ed., Wiley: New York, 1991.

20. Assis, M. D.; Smith, J. R. L.; J. Chem. Soc., Perkin Trans. 2 1998, 2221.

21. Evans, S.; Lindsay Smith, J. R.; J. Chem. Soc., Perkin Trans. 2 2000, 1541.

22. Groves, J. T.; Han, Y. Z.; Montellano, P. R.; Cytochrome Structure, Mechanism and Biochemistry, Plenum Press: New York, 1995, ch. 1, p. 450.

23. Bedioui, F.; Coord. Chem. Rev. 1995, 144, 39.

24. Dias, P. M.; Faria, D. L. A.; Constantino, V. L. R.; J. Inclusion Phenom. Macrocyclic Chem. 2000, 38, 251.

25. Doro, F. G.; Lindsay Smith, J. R.; Ferreira, A. G.; Assis, M. D.; J. Mol. Catal. A: Chem. 2000, 164, 97.
26. Mac Leod, T. C. O.; Guedes, D. F. C.; Lelo, M. R.; Rocha, R. A.; Caetano, B. L.; Ciuffi, K. J.; Assis, M. D.; J. Mol. Catal. A: Chem. 2006, 259, 319.

27. Cooke, P. R.; Lindsay Smith, J. R.; Tetrahedron Lett. 1992, 33, 2737.

28. Meunier, B.; Chem. Rev. 1992, 92, 1411.

29. Tatsumi, T.; Nakamura, M.; Tominaga, H.; Catal. Today 1989, $61,63$.

30. Schiavon, M. A.; Iamamoto, Y.; Nascimento, O. R.; Assis, M. D.; J. Mol. Catal. A: Chem. 2001, 174, 213.

31. Hill, C. L.; Shardt, B. C.; J. Am. Chem. Soc. 1980, 102, 6374.

32. Zucca, P.; Mocci, G.; Rescigno, A.; Sanjust, E.; J. Mol. Catal. A: Chem. 2007, 278, 220.

33. Zucca, P.; Vinci, C.; Sollai, F.; Rescigno, A.; Sanjust, E.; J. Mol. Catal. A: Chem. 2008, 288, 97.

34. Gonsalves, A. M. A. R.; Johnstone, R. A. W.; Pereira, M. M.; Shaw, J.; J. Chem. Soc., Perkin Trans. 1991, 1, 645.

35. Battioni, P.; Renaud, J. P.; Bartoli, J. F.; Reina-Artiles, M.; Fort, M.; Mansuy, D.; J. Am. Chem. Soc. 1988, 110, 8462.

36. Rocha Gonsalves, A. M.; Serra, A. C.; J. Chem. Soc., Perkin Trans. 2 2002, 715.

37. Monti, D.; Pastorini, A.; Mancini, G.; Borocci, S.; Tagliatesta, P.; J. Mol. Catal. A: Chem. 2002, 179, 125.

38. Kurek, S. S.; Michorczyk, P.; Balisz, A. M.; J. Mol. Catal. A: Chem. 2003, 194, 237.

39. Pirouzmand, M.; Amini, M. M.; Safari, N.; J. Colloid Interface Sci. 2008, 319, 199.

40. Nakayama, N.; Tsuchiya, S.; Ogawa, S.; J. Mol. Catal. A: Chem. 2007, 277, 61 .

41. Mansuy, D.; Leclaire, J.; Fontecave, M.; Dansette, P.; Tetrahedron 1984, 40, 2847.

42. Groves, J. T.; Myers, R. S.; . 1983, 105, 5791.

43. Groves, J. T.; Kruper, W. J.; Nemo, T. E.; Myers. R. S.; J. Mol. Catal. A: Chem. 1980, 7, 169.

44. Mansuy, D.; Battioni, J. P.; J. Chem. Soc. Commun. 1984, 1161.

45. Crook, P. R.; Gilmartin, C.; Gray, G. W.; Lindsay Smith, J. R.; J. Chem. Soc., Perkin Trans. 2 1995, 1573.

46. Collmman, J. P.; Kodadek, T.; Raybuck, S. A.; Brauman, J. I.; Papazian, L. M.; J. Am. Chem. Soc. 1985, 107, 4343.

47. Nam, W.; Lim, M. H.; Shin, W.; Angew. Chem., Int. Ed. 2000, 20,39 .

Received: June 27, 2008

Web Release Date: April 3, 2009

FAPESP helped in meeting the publication costs of this article. 